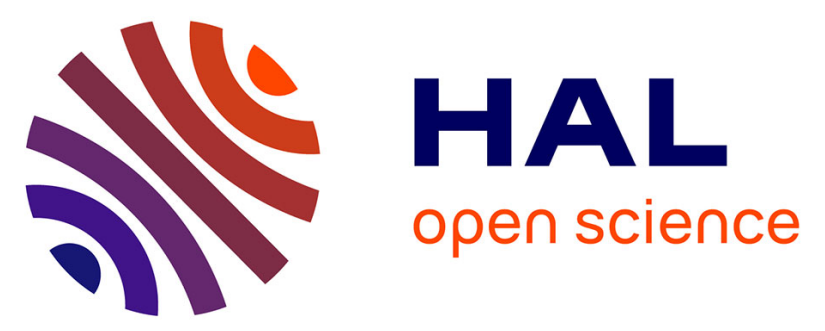

\title{
Parents' attitudes towards varicella vaccination acceptance in France and Germany: effect of vaccine recommendation and reimbursement (a survey)
}

François-André Allaert, Antoine Blanc, Yves Megard, Isabelle Bertand

\section{- To cite this version:}

François-André Allaert, Antoine Blanc, Yves Megard, Isabelle Bertand. Parents' attitudes towards varicella vaccination acceptance in France and Germany: effect of vaccine recommendation and reimbursement (a survey). Journal of Public Health, 2008, 17 (2), pp.71-76. 10.1007/s10389-008-0218-5 . hal-00478182

\section{HAL Id: hal-00478182 \\ https://hal.science/hal-00478182}

Submitted on 30 Apr 2010

HAL is a multi-disciplinary open access archive for the deposit and dissemination of scientific research documents, whether they are published or not. The documents may come from teaching and research institutions in France or abroad, or from public or private research centers.
L'archive ouverte pluridisciplinaire HAL, est destinée au dépôt et à la diffusion de documents scientifiques de niveau recherche, publiés ou non, émanant des établissements d'enseignement et de recherche français ou étrangers, des laboratoires publics ou privés. 


\title{
Parents' attitudes towards varicella vaccination acceptance in France and Germany: effect of vaccine recommendation and reimbursement (a survey)
}

\author{
François-André Allaert • Antoine Blanc • Yves Megard • \\ Isabelle Bertand
}

Received: 13 February 2008 / Accepted: 15 July 2008 / Published online: 30 August 2008

(C) Springer-Verlag 2008

\begin{abstract}
Aims To ascertain physicians' and parents' attitudes towards varicella vaccination acceptance and to compare them between Germany $(G)$, where routine varicella vaccination is recommended in children, and France $(\mathrm{F})$, where it is not.

Methods Study design: cross-sectional pharmacoepidemiological study conducted in pediatric practice. Data included descriptions of the vaccinated children by pediatricians and descriptions of the parents' attitudes using a self-administered questionnaire. The next five successive children, under 15 years old, vaccinated against varicella were included in the study.

Results Six hundred ninety-five pediatricians (F: 186; G: 509) and 2,593 parents (F: 664; G: 1,929) were included in the study. Initially, $7.1 \%$ of the German parents and $15.3 \%$ of the French parents were reluctant to have their children inoculated with the varicella vaccine $(p<0.0001)$. The main reason for their reluctance was the 'fear of complications due to the vaccination' in both countries (G: $60.0 \%$ vs $55.5 \%$; p: ns). Fewer German parents thought that the varicella vaccine was too recent $(5.9 \%$
\end{abstract}

F.-A. Allaert $(\bowtie)$

Department of Medical Evaluation, Ceren ESC and Cenbiotech,

24 bd Jeanne d'Arc,

21000 Dijon, France

e-mail: stat@cenbiotech.com

F.-A. Allaert

Department of Epidemiology, McGill University,

Montreal, QC, Canada

A. Blanc $\cdot$ Y. Megard $\cdot$ I. Bertand

Sanofi-Pasteur MSD,

Lyon, France vs $45.5 \% ; \mathrm{p}<0.0001)$, and they were also less reluctant due to the cost of the vaccination (G: $11.9 \%$ vs F:22.8\%; $\mathrm{p}<0.02$ ). In both countries, the most convincing arguments for parents who were initially reluctant were 'information on the potential seriousness of the disease,' which was reported by three-quarters of the parents (G: $70.0 \%$ vs F: 74.3\%; $\mathrm{p}$ : ns), and 'availability of an effective, well-tolerated vaccine' (G: $59.4 \%$ vs F: 64.0\%; p: ns).

Conclusion Even in the absence of an official recommendation, French parents will accept varicella vaccine to the same extent as German parents where it is advisable if they receive appropriate information about the potential severity of the disease and the efficacy and safety of the vaccine.

Keywords Varicella vaccination - General practice .

Parents' attitude

\section{Introduction}

Many studies have shown that vaccines can protect children and adults from bacterial and viral infections. Vaccination has led to important reductions in the incidences of several diseases and even eradication in same instances, for example, small pox. Despite their proven effectiveness, many children do not receive vaccines because of their parents' philosophy or religious beliefs, their concerns about costs, or doubts about the usefulness, safety, or efficacy of vaccines (Poland and Jacobson 2001; Taylor et al. 2002; Alfredsson et al. 2004; Fredrickson et al. 2004; Freed et al. 2004). Reluctance to use vaccines has been fueled by reports of alleged adverse events from vaccines spread by anti-vaccination web sites, as well as by recent vaccine recalls and modifications (Freed et al. 1996; Wolfe et al. 2002; Flanagan-Klygis et al. 2005). The situation is 
worse when the vaccine is not universally recommended, and even when a vaccine is recommended, not all physicians immediately adopt it in routine use.

Varicella vaccine is one example for which these issues have slowed uptake. In the US, varicella vaccination has been recommended since 1996, but it took nearly 5 years to reach satisfactory coverage of more than $80 \%$ of children (Sengupta et al. 2007). This vaccination has led to a reduction in the incidence of varicella of about $75 \%$ (CDC 2003). Doctors must be ready to answer parents' questions and address misconceptions since parental beliefs may be a major factor influencing whether a child receives the varicella vaccine (Taylor and Newman 2000).

The varicella vaccine is being increasingly used throughout Europe, although with different administrative and regulatory modalities. For example, in France, the varicella vaccine has been registered since December 2003, but there are no national recommendations for its routine use in children. Recommendations exist for health-care and childcare workers, those who have close contacts with immunocompromised people, and children requiring a solid organ transplant, and for people, at least 18 years old, within 3 days of contact with an infected person. In addition, this vaccine is not reimbursed by the health-care insurance system. In contrast, in Germany, routine administration to healthy children has been officially recommended since July 2004, and it is reimbursed in most administrative areas (Rasch and Hellenbrand 2004). Thus, Germany and France provide an interesting comparison for studying the effect of recommendations and funding on the attitudes of parents concerning varicella vaccination. For this we surveyed parents of children that were vaccinated against varicella by private pediatricians or general practitioners in Germany and France between March 2005 and March 2006.

\section{Materials and methods}

The purpose of this cross-sectional study conducted between March 2005 and March 2006 was to ascertain physicians' and parents' attitudes towards varicella vaccination acceptance and to compare them between Germany $(\mathrm{G})$, where routine varicella vaccination is recommended in children, and France (F), where it is not. Two samples of 600 pediatricians (or GPs with essentially child-oriented practices) selected at random in France and Germany were involved. They were asked to include the next five successive children they vaccinated against varicella during the next month. These recruitment conditions led in each country to a sample of 3,000 cases providing a confidence interval of under $2 \%$ in case of an observed percentage under $5 \%$. This choice was made due to the fact that we expected a low value for some questions, in particular for the spontaneous request for varicella vaccination, especially in France, where it is not reimbursed. These children had to be under 15 years of age and had to have no contraindications to the vaccine. Information on the main demographic and clinical characteristics of the vaccinated children as well as why the parents accepted the vaccination was recorded by the physician on the physician's questionnaire. Information on the parents' attitudes concerning the varicella vaccination was recorded on a self-administered questionnaire that the pediatrician gave them after having explained how to fill it in. This questionnaire was returned directly to the data analysis center in a prepaid envelope to protect anonymity. A common number included in the two documents allowed matching the pediatrician form with the self-administered questionnaire for the purposes of the statistical analysis.

Results are expressed as means with their standard deviations for quantitative variables and by numbers and frequency distributions for qualitative variables. Chi-square analysis and analysis of variance were respectively performed to compare qualitative and quantitative values between France and Germany. A $P$-value of less than 0.05 was considered to indicate statistical significance.

\section{Results}

Population and context of the vaccination

Between March 2005 and March 2006, 509 German pediatricians participated in the study and only 186 French pediatricians because of some recruitment difficulties in relation to the absence of varicella vaccination recommendations in France. This point will be discussed. The questionnaire was given to the parents of 3,033 vaccinated children. A total of 2,593 questionnaires was returned (85.6\% response rate; 1,929 from Germany and 664 from France). The mean age, percentage of girls, family size, and rank of the vaccinated children were similar for the two countries (Table 1 ). The only variable that was significantly different was the parent's education level: $36.1 \%$ of parents in Germany vs. $55.3 \%$ of parents in France were university or advanced technical college graduates $(P<0.0001)$.

The rate of spontaneously requested varicella vaccination was significantly higher for German parents than for French parents $(20.9 \%$ vs $12.6 \% ; P<0.0001)$. As shown in Fig. 1, except for 'avoid illness' and 'child living in close contact with other children,' which are the two main reasons for spontaneous requests for vaccination, nearly all the other reasons given by parents were significantly different between the two countries: 'Prevent complications' was mentioned more often in Germany than in 
Table 1 Family characteristics of vaccinated children

\begin{tabular}{|c|c|c|c|}
\hline Variable & Germany & France & $\mathrm{P}$ \\
\hline Childs' age (years \pm SD) & $3.3 \pm 3.1$ & $3.3 \pm 3.1$ & NS \\
\hline Girls $(\%)$ & 52.3 & 50.3 & NS \\
\hline Parents' education: university or technical college graduate (\%) & 36.1 & 55.3 & $<0.0001$ \\
\hline Number of children in the family (mean \pm SD) & $1.8 \pm 0.9$ & $1.7 \pm 1.0$ & NS \\
\hline Rank of the vaccinated child (mean \pm SD) & $1.6 \pm 0.8$ & $1.7 \pm 0.8$ & NS \\
\hline
\end{tabular}

SD: standard deviation; NS: not statistically significant

Comparison between Germany and France

France $(51.4 \%$ vs $41.5 \% ; P<0.01)$, and the difference was even larger for 'information on the varicella vaccine in the media' (42.3\% vs $19.2 \% ; P<0.0001)$. The reasons for a spontaneous request for varicella vaccination were less often in Germany than in France 'avoid social and professional impact of child's illness' (29.1\% vs $47.7 \%$; $P<0.0001)$, 'child's relative currently has varicella' $(5.6 \%$ and $21.5 \% ; P<0.0001)$, and 'avoid scarring' $(20.5 \%$ vs $29.6 \% ; \mathrm{p}<0.05)$.

Parents' opinions concerning varicella vaccination

The analysis of the parents' questionnaire (Fig. 2) reveals that $7.1 \%$ of the German and $15.3 \%$ of the French parents were initially reluctant to allow their children to receive the varicella vaccine $(P<0.0001)$. The two main reasons for their reluctance were similar in the two countries, and both concerned the vaccination itself: 'Complications following vaccination' (G: $60.0 \%$ vs F: $55.5 \%$; p: ns) and 'too many vaccinations' (G: $43.0 \%$ vs F: $40.6 \%$; p: ns). The varicella vaccine was considered as being too recent by more French than German parents (G: 5.9\% vs F: 45.5\%; p<0.0001). Also, more French parents were reluctant due to the cost of the vaccination (G: $11.9 \%$ vs F: $22.8 \%$; $<0.02$ ) or because they considered their child too young (G: $5.9 \%$ vs F: $13.9 \% ; \mathrm{p}<0.05)$.

In both countries, the most convincing arguments for parents who were initially reluctant or who did not know that a varicella vaccine existed were 'information on the potential seriousness of the disease,' which was reported by three-quarters of the parents, and 'availability of an effective, well-tolerated vaccine,' which was mentioned by $59.4 \%$ and $64.0 \%$ of the parents in Germany and France, respectively ( $\mathrm{p}$ : $\mathrm{ns}$ ) (Fig. 3). The other reasons, in decreasing order of importance, were information that 'varicella is frequent and contagious' and 'prevention of varicella scars' and 'impact on the family of the disease.' Finally, the fact that vaccination is free of charge in Germany was indicated as an advantage by $23.4 \%$ of the German parents.
Fig. 1 Reasons for parents' spontaneous request for varicella vaccination. Comparison between Germany and France

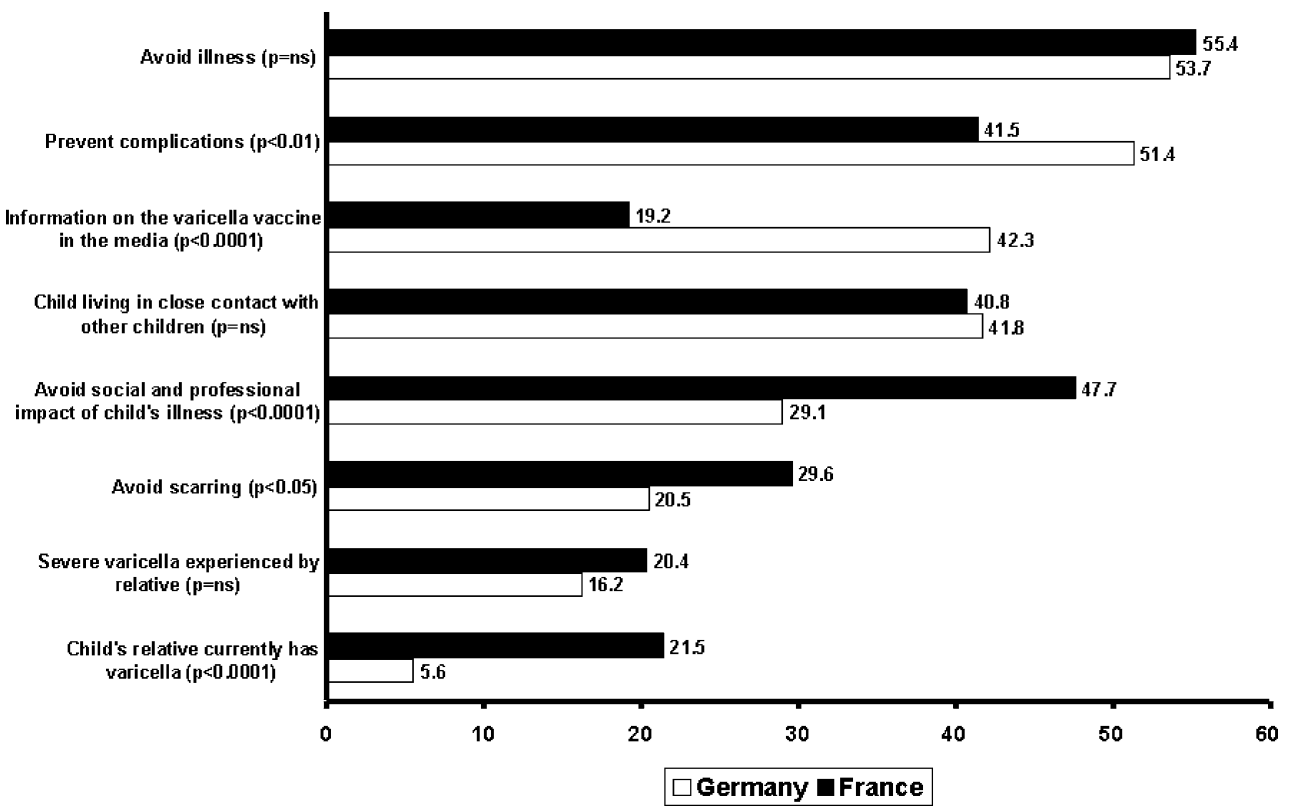


Fig. 2 Reasons for parents' initial reluctance to accept varicella vaccination. Comparison between Germany and France

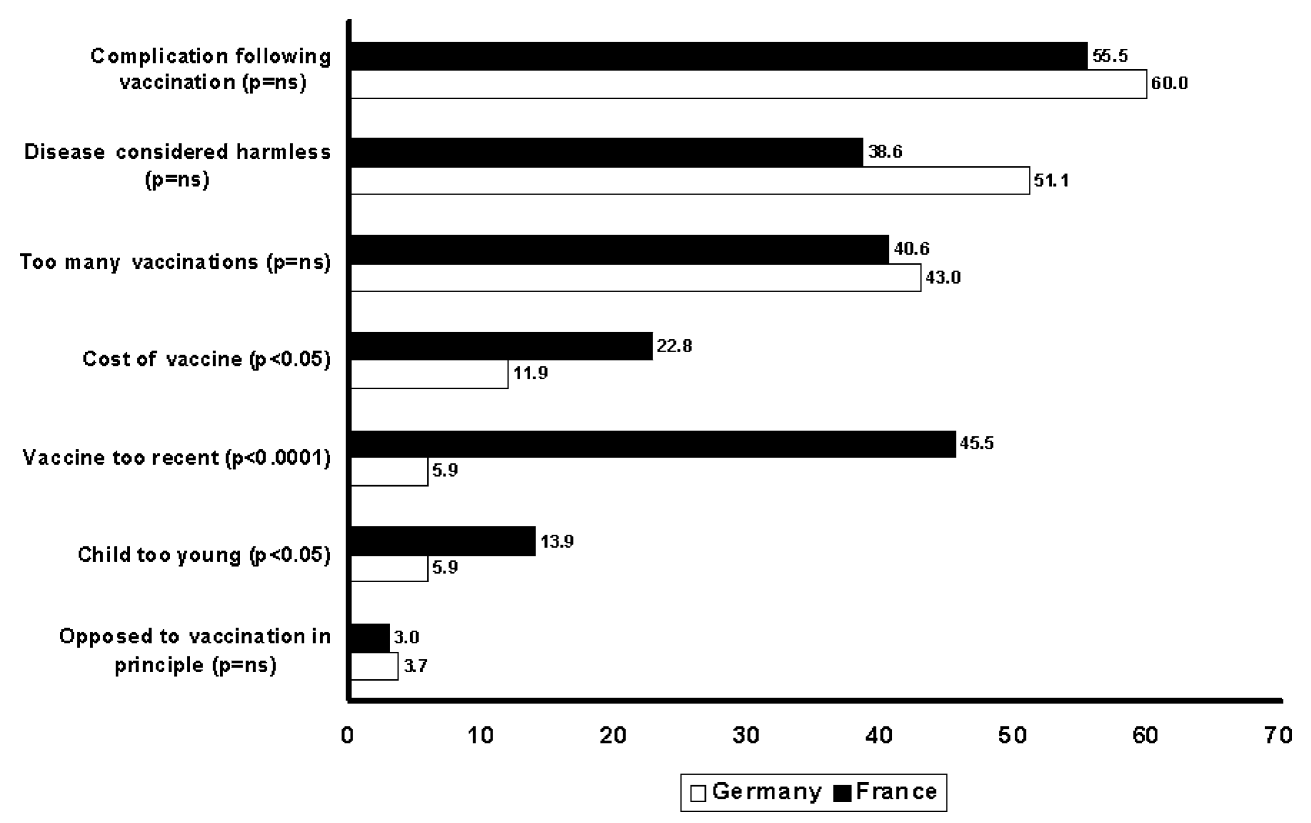

\section{Discussion}

In the current study, we investigated parents' attitudes to accepting varicella vaccination between France and Germany and the best way to convince them to have their children vaccinated.

The comparison with Germany was chosen because it was the first country in Europe that added varicella vaccination to the national routine vaccination schedule for all children; it was the first country in the European Union to do this. The Ständige Impfkommission (Standing Committee on Vaccination, STIKO) at the Robert Koch Institute in Germany announced the change in their published update to the national vaccine schedule (Robert
Koch-Institut 2004a, b). According to these official recommendations, varicella vaccination is scheduled for infants aged between 11 and 14 months (given preferably at the same time as the MMR vaccine). Catch-up vaccination for children and adults is recommended, in particular for persons aged 9-17 years who have not had varicella infection. In France, no such recommendation exists, and the comparison with Germany was done in order to evaluate the impact of this recommendation and, moreover, to analyze if the existence a such recommendations was a sine qua non condition to the spreading of the varicella vaccine.

Potential biases should be considered before generalizing the results to all parents of young children.
Fig. 3 Most convincing arguments in favor of varicella vaccination. Comparison between Germany and France

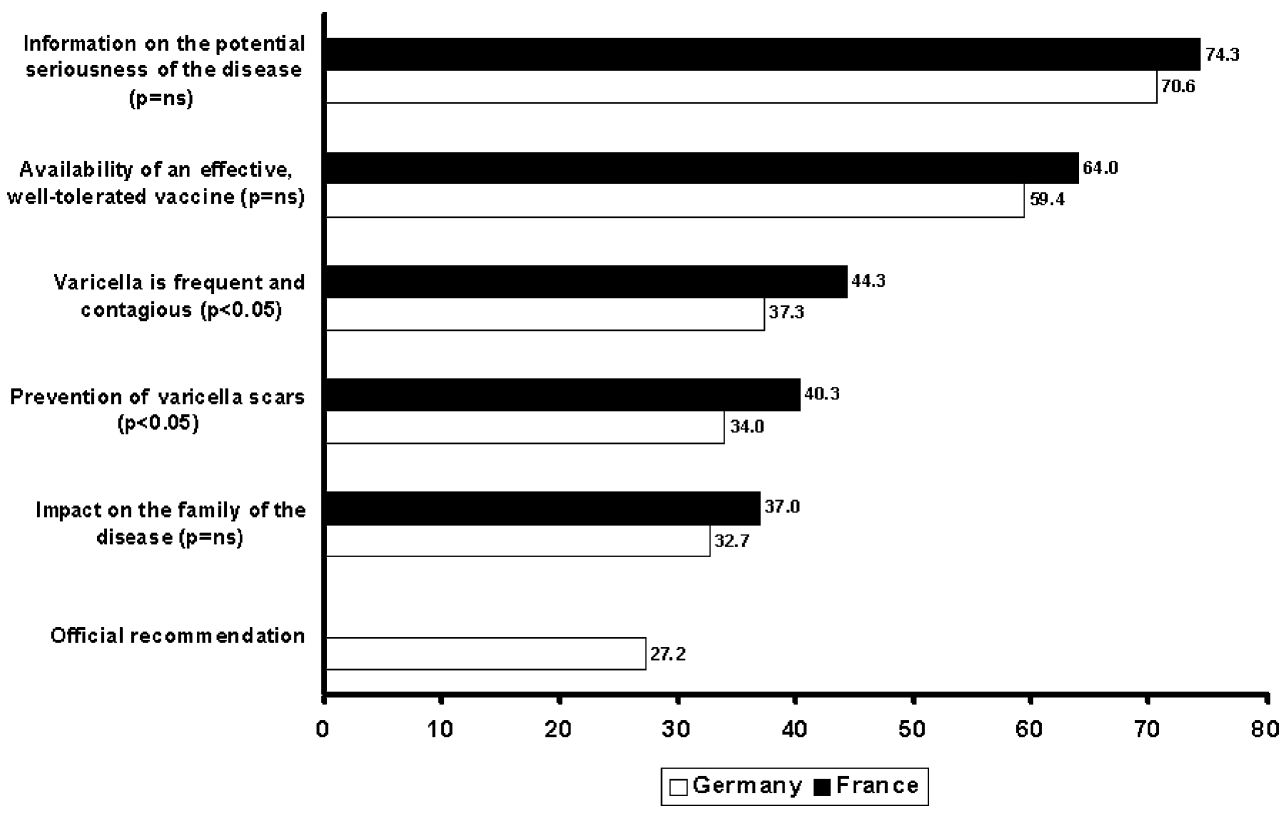


The most important possible bias is that the physicians who agreed to participate in the study may be those who are most in favor of varicella vaccination and therefore the most inclined to convince the parents. This bias is unavoidable, but its influence would be the same in both countries. This potential bias may also have had some impact on the parents' opinion, but the effect would have been minimal because the parents completed a strictly anonymous self-administered questionnaire that they sent directly to the data analysis center.

One other bias could be linked to the fact that the rate of pediatricians participating to the study in France was much lower than in Germany. The lack of a recommendation in favor of varicella vaccination in France (and consequently the absence of reimbursement) explains why many practitioners are still reluctant to propose it to parents and thus the difficulties we met recruiting regular varicella vaccine prescribers. These recruitment difficulties have an unavoidable effect on the precision of the results, providing an average confidence interval of $2 \%$ for the German data and of $4 \%$ for the French data rather than the initially expected $<2 \%$. However, taking into account that the lowest percentage described for the French sample is $12.6 \%$ of spontaneously requested varicella vaccination, this precision of $4 \%$ still appears satisfactory.

Another limit of our study is also due to the fact that we only considered vaccinated children, while it could have been interesting to describe the attitude and intentions from the parents who refused the vaccination of their child. This choice to focus our study on vaccination acceptance and eventual previous reluctance and not on refusal was dictated by the lack of recommendation for varicella vaccination in France. Also, a written inquiry about the patient's refusal could have been interpreted by the health authority as an unacceptable attempt to strongly influence them, and the rate of spontaneous answer would have been very low.

Despite potential biases and limits, our results revealed that the presence of a recommendation for the vaccination in Germany and its absence in France have a major impact on the parents' knowledge about the disease and its complications as well as on health-care promotion of the vaccine.

A first remark concerns the educational level of the parents of the vaccinated children, which was higher in France than in Germany. This reflects that in France, due to the lack of official recommendation and of reimbursement, the educational level and the level of income of parents has a strong influence on the acceptance of varicella.

Due to the availability of an official recommendation, more German parents were aware of the varicella vaccine and spontaneously requested vaccination. In addition, their reasons for requesting vaccination were different. German parents identified the main purpose of the vaccine as preventing complications and were convinced by information from the media, whereas the French parents' motivations were linked to the social and professional consequences of the disease, the prevention of infection of others, or the fear of scars. These findings suggest that even the French parents who spontaneously requested the vaccine were not aware of the seriousness of the complications of varicella. In Germany, the parents' attitudes are similar to those described for parents in the US (Taylor and Newman 2000). In particular, when a recommendation exists, parents are more convinced about the advantages of the vaccine to prevent serious complications than its ability to reduce time lost from work.

The percentage of parents reluctant to accept varicella vaccination in the current study does not reflect the percentage in the global population; it reflects the initial rate of reluctance of parents who finally agreed to have their children vaccinated. Thus, the percentages reported here cannot be used as the basis for making conclusions about the reluctance for vaccination in the overall population. The parents' reluctance is mostly due to the fact that they consider varicella to be a harmless disease and, above all, fear of complications from the vaccine. The percentages of parents who were reluctant due to fear of complications of the vaccine $(55.5 \%$ in France and $60.0 \%$ in Germany) are similar to that reported in the US (69\%) (Salmon et al. 2005). The high proportion of French parents who said they were reluctant because the varicella vaccine is too recent (45.5\%) is surprising, but is probably due to the fact that since varicella vaccine is not officially recommended in France, little information on varicella vaccination is targeted to the general population. This is illustrated by the fact that nearly half the French parents in our study were unaware that a varicella vaccine has been available for more than 10 years in the US, compared with $5.9 \%$ in Germany.

Differences in reluctance to have children vaccinated due to cost were not as big as expected. However, this finding may be biased by the socioeconomic profile of the French participants; on average, they have a higher educational level and therefore a higher income than their German counterparts. We cannot, therefore, conclude that French parents are probably more willing to pay than German parents. This finding could suggest that, in the absence of reimbursement, the use of the vaccine will be dependent on the parents' incomes.

Our results show that in both countries the most convincing argument in favor of the varicella vaccine is the information given by the practitioner regarding the seriousness of the disease and the availability of a welltolerated vaccine. The results from a study in the US, where the varicella vaccine has been recommended for more than 10 years, were similar; the most frequent factor influencing 
parents' decision was their doctor's advice (Freeman and Freed 1999).

In summary, our results show that both German and French parents readily accepted varicella vaccination when the practitioner recommended it and/or when they were appropriately informed about the potential severity of varicella disease and the safety of the vaccine, irrespective of an official recommendation and reimbursement for the vaccine. However, the absence of reimbursement may affect some parents' decision, due to the cost, and therefore, this may lead to social inequality.

Conflict of Interest The authors Antoine Blanc, Yves Megard, and Isabelle Bertand are full-time employees of Sanofi Pasteur MSD. This study was funded by a grant from Sanofi Pasteur MSD.

\section{References}

Alfredsson R, Svensson E, Trollfors B, Borres MP (2004) Why do parents hesitate to vaccinate their children against measles, mumps and rubella? Acta Paediatr 93:1232-1237

Centers for Disease Control and Prevention (CDC) (2003) Decline in annual incidence of varicella-selected states, 1990-2001. MMWR Morb Mortal Wkly Rep 52:884-885

Flanagan-Klygis EA, Sharp L, Frader JE (2005) Dismissing the family who refuses vaccines: a study of pediatrician attitudes. Arch Padiatr Adolesc Med 159:929-934

Fredrickson DD, Davis TC, Arnould CL, Kennen EM, Hurniston SG, Cross JT, Bocchini JA Jr (2004) Childhood immunization refusal: provider and parent perceptions. Fam Med 36:431-439

Freed GL, Katz SL, Clark SJ (1996) Safety of vaccinations: Miss America, the media and the public health. JAMA 276:1869-1872
Freed GL, Clark SJ, Hibbs BF, Santoli JM (2004) Parental vaccine safety concerns. The experiences of pediatricians and family physicians. Am J Prev Med 26:11-14

Freeman VA, Freed GL (1999) Parental knowledge, attitudes and demand regarding a vaccine to prevent varicella. Am J Prev Med 17:153-155

Poland GA, Jacobson RM (2001) Understanding those who do not understand: a brief review of the anti-vaccine movement. Vaccine 19:2440-2445

Rasch G, Hellenbrand W (2004) Germany adds varicella vaccine to the National vaccination programme. Eurosurveillance Vol. 8, issue 31. Available at: http://www.eurosurveillance.org/ew/2004/ 040729.asp

Robert Koch-Institut (2004a) Neue Empfehlungen der Ständigen Impfkommission veröffentlicht. Press release. 26 July. http:// www.rki.de

Robert Koch-Institut (2004b) Empfehlungen der Ständigen Impfkommission (STIKO) am Robert Koch-Institut/Stand: Juli 2004. Epidemiol Bull (30):235-250

Salmon DA, Moulton LH, Omer SB, deHart MP, Stokley S, Halsey NA (2005) Factors associated with refusal of childhood vaccines among parents of school-aged children. Arch Pediatr Adolesc Med 159:470-476

Sengupta N, Booy R, Schmitt HJ, Peltola H, Van-Damme P, Schumacher RF, Campins M, Rodrigo C, Heikkinen T, Seward J, Jumaan A, Finn A, Olcen P, Thiry N, Weil-Olivier C, Breuer J (2007) Varicella vaccination in Europe: are we ready for a universal childhood programme? Eur J Pediatr 167(1):47-55, 2008 Jan

Taylor JA, Newman RD (2000) Parental attitudes toward varicella vaccination. Arch Pediatr Adolesc Med 154:302-306

Taylor JA, Darden PM, Brooks DA, Hendricks JW, Wasserman RC, Bocian AB (2002) Association between parents' preferences and perceptions of barriers to vaccination and the immunization status of their children: a study from Pediatric Research in Office Settings and the National Medical Association. Pediatrics 110:1110-1116

Wolfe RM, Sharp LK, Lipsky MS (2002) Content and design attributes of antivaccination websites. JAMA 287:569-575 